\title{
Hidrocefalia extraterrestre
}

\section{Extraterrestrial Hydrocephalus}

\author{
W. A. Prada Mancilla ${ }^{1}$ \\ ${ }^{1}$ Universidad de la Sabana, Bogotá, Colombia \\ Rev Argent Radiol 2019;83:89.
}

Se trata de una paciente prematura extrema que nació a las 26 semanas de gestación con presentación de hemorragia de la matriz germinal y dilatación ventricular. La paciente evolucionó satisfactoriamente en la unidad neonatal, por lo cual, se da egreso y control con nueva ecografía transfontanelar. En el control post natal tres meses después, se le realiza una ecografía transfontanelar, evidenciándose hidrocefalia poshemorrágica. Se presenta un corte coronal de una ecografía transfontanelar (-Fig. 1)

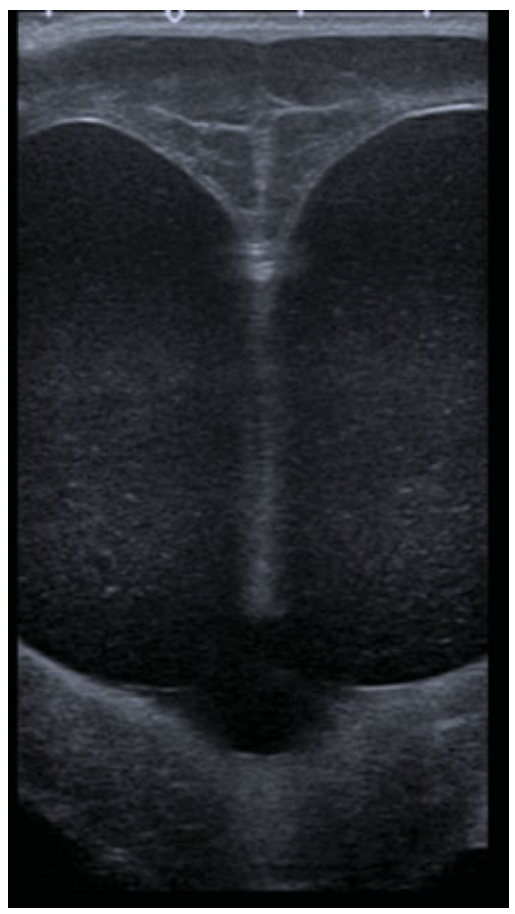

Fig. 1 Corte coronal de ecografía transfontanelar.

received

October 21, 2017

accepted

November 9, 2017
DOI https://doi.org/

$10.1055 / \mathrm{s}-0038-1639488$. ISSN 1852-9992.
Address for correspondence W. A. Prada Mancilla, Universidad de la Sabana, Bogotá, Colombia (e-mail: wpradamancilla@gmail.com).

con transductor lineal de alta frecuencia, donde se evidencia una imagen similar a la cara de un extraterrestre (-Fig. 2). La representación de los ojos pertenece a la dilatación severa de los ventrículos con un índice ventricular de Levene positivo. La nariz es representada por el tercer ventrículo dilatado. Adicionalmente, la frente del extraterrestre es representada por el parénquima cerebral, el cual se encuentra adelgazado sin alteración de los giros de la línea media.

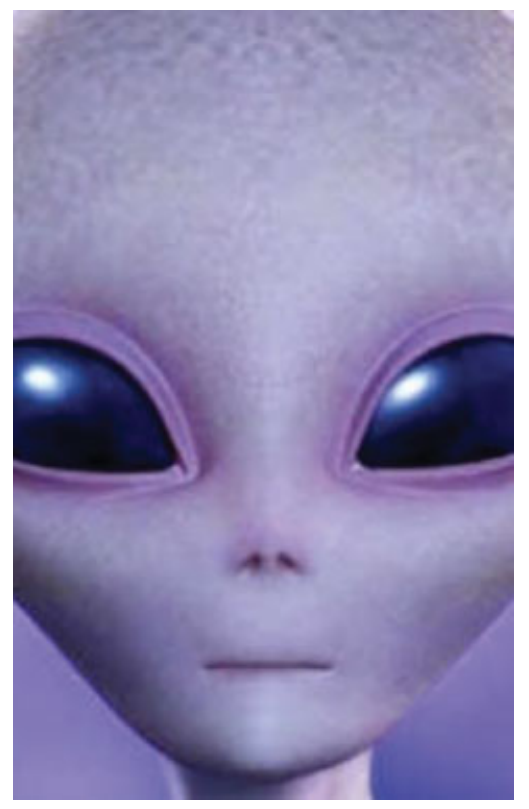

Fig. 2 Imagen de la cara de un extraterrestre.

Copyright $\odot$ 2019, Sociedad Argentina de Radiología. Publicado por Thieme Revinter Publicações Ltda., Rio de Janeiro, Brazil. Todos los derechos reservados.

\section{License terms}

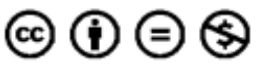

